Prepared for the U.S. Department of Energy

under Contract DE-AC05-76RL01830

\title{
Hierarchical Analysis of the Omega Ontology
}

C Joslyn

$\mathrm{P}$ Paulson

December 2009

Pacific Northwest

NATIONAL LABORATORY

Proudly Operated by Battelle Since 1965 


\title{
DISCLAIMER
}

This report was prepared as an account of work sponsored by an agency of the United States Government. Neither the United States Government nor any agency thereof, nor Battelle Memorial Institute, nor any of their employees, makes any warranty, express or implied, or assumes any legal liability or responsibility for the accuracy, completeness, or usefulness of any information, apparatus, product, or process disclosed, or represents that its use would not infringe privately owned rights. Reference herein to any specific commercial product, process, or service by trade name, trademark, manufacturer, or otherwise does not necessarily constitute or imply its endorsement, recommendation, or favoring by the United States Government or any agency thereof, or Battelle Memorial Institute. The views and opinions of authors expressed herein do not necessarily state or reflect those of the United States Government or any agency thereof.

\author{
PACIFIC NORTHWEST NATIONAL LABORATORY \\ operated by \\ BATTELLE \\ for the \\ UNITED STATES DEPARTMENT OF ENERGY \\ under Contract DE-AC05-76RL01830
}

Printed in the United States of America
Available to DOE and DOE contractors from the Office of Scientific and Technical Information,
P.O. Box 62, Oak Ridge, TN 37831-0062;
ph: (865) 576-8401
fax: $(865)$ 576-5728
email: reports@adonis.osti.gov

\begin{abstract}
Available to the public from the National Technical Information Service, U.S. Department of Commerce, 5285 Port Royal Rd., Springfield, VA 22161 ph: (800) 553-6847 fax: $(703) 605-6900$ email: orders@ntis.fedworld.gov online ordering: http://www.ntis.gov/ordering.htm
\end{abstract}

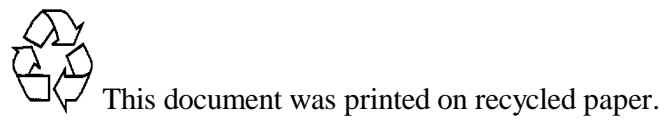




\section{Hierarchical Analysis of the Omega Ontology}

C Joslyn

P Paulson

December 2009

Prepared for the U.S. Department of Energy

under Contract DE-AC05-76RL01830

Pacific Northwest National Laboratory

Richland, Washington 99352 


\title{
Hierarchical Analysis of the Omega Ontology*
}

\author{
Cliff Joslyn ${ }^{\dagger}$ and Patrick Paulson $\ddagger$
}

December, 2009

\section{Contents}

1 Data Preparation

2 Transitivity Analysis

3 Order Theoretical Analysis

4 Subclass

5 Subject

6 Member

7 Part Of

\begin{abstract}
We provide an analysis of the hierarchical structure of a version of the Omega Ontology currently in use within the US Government. After providing an initial statistical analysis of the distribution of all link types in the ontology, we then provide a detailed order theoretical analysis of each of the four main hierarchical links present. This order theoretical analysis includes the distribution of components and their properties, their parent/child and multiple inheritance structure, and the distribution of their vertical ranks.
\end{abstract}

\section{Data Preparation}

We received the initial data dump of the Omega ontology [4] currently in use, and converted it to OWL. In our current version of the transformation, we assume that all subclasses of the PROPERTY should be expressed as object properties. Any Omega concept that is not an object property is

\footnotetext{
*Initial report for the Ontology Analytics (Ontolytics) project. PNNL Technical Report PNNL-19041.

${ }^{\dagger}$ Chief Scientist for Knowledge Sciences, National Security Directorate, Pacific Northwest National Laboratory, PNNL/Battelle Suite 400, 1100 Dexter Ave. N, Seattle, WA 98109 cjoslyn@pnl.gov, 206-528-3042

${ }^{\ddagger}$ Senior Research Scientist, Knowledge Systems Group, Pacific Northwest National Laboratory, PO Box 999 MS K7-28, Richland, WA 99352 USA, patrick.paulson@pnl.gov, 509-375-3926
} 
transformed into an owl:Class. This approach will be revised as we incorporate special knowledge about the SUBJECT-MATTER slot and other characteristics of the Omega ontology.

There are several problems with this approach - sometimes the same name is used for both a concept and a property, such as LOCATION. To address such problems, we are creating a metaontology describing the contents of the Omega ontology. In this ontology, all classes and properties are transformed into instances of classes that Stand in for OWL's classes, object properties, and datatype properties. The resulting knowledge base can be examined using OWL-aware tools to determine what aspects will not result in a valid OWL-DL ontology.

\section{Transitivity Analysis}

In consultation with the sponsor, we performed an initial analysis of the node and link types. We identified 660,541 links and 121,658 node declarations (classes and properties). There are also 5 SUBJECT concepts that do not appear in the class hierarchy. The links include DESCRIPTION records from the omega ontology.

We considered link types together with their inverses, as shown in Table 1. Link types with inverses are shown over two sets of columns, and those without over one. In many cases, the number of forward and reverse links for inverse paris are not the same, and this is measured showing the count range and the $\%$ of that range.

After consultion with the sponsor we gained a better understanding of Omega's structure. After understanding that the subject hierarchy was distinct from the class hierarchy, we retained it, bu excluded the DEFINITION, DOMAIN, RANGE, INVERSE and SOURCE links.

We combined link types with inverses together. For example, DIRECT-SUPERCLASS and SUBCLASSES are combined into just SUBCLASSES (selected arbitrarily), and recorded with the mean of the forward and reverse link counts.

The distribution of the resulting 276,858 combined links is shown in Table 2. This reveals that by far the biggest link types are SUBCLASSES and SUBJECT (as expected). Together with the next two, DIRECT-HAS-MEMBER and DIRECT-PART-OF, they comprise $93.2 \%$ of all the links. Additionally, each of these links is transitive, that is, hierarchical.

\section{Order Theoretical Analysis}

We now outline aspects of our order theoretical analysis.

We have four candidate semantic hierarchies: SUBCLASSES, SUBJECT, DIRECT-HAS-MEMBER and DIRECT-PART-OF. Each breaks into a number of connected components, and each component is represented as a distinct finite ordered set $\langle P, \leq\rangle[1]$, for example as shown in Fig. 1. In this context, we can initially measure the number of parents and children of each node, revealing the amount of multiple inheritance present.

Further, we are motivated by the our conception of the proper vertical positioning of nodes $[2,3]$. Note that in some sense, all children of the root $(L, B, X, K)$ are the same "distance" from the root node 1. But they are not all the same. For example, $K$ is also a leaf, and is similar to e.g. $Q$ in that it is the same distance "from the bottom". 


\begin{tabular}{|c|c|c|c|c|c|c|}
\hline Name & Count & Inverse & $\begin{array}{r}\text { Inverse } \\
\text { Count }\end{array}$ & $\begin{array}{r}\text { Count } \\
\text { Mean }\end{array}$ & $\begin{array}{l}\text { Count } \\
\text { Range }\end{array}$ & $\%$ Range \\
\hline DIRECT-SUPERCLASS & 125696 & SUBCLASSES & 125696 & 125696 & 0 & $0.00 \%$ \\
\hline DEFINITION & 115083 & & & 115083 & 0 & $0.00 \%$ \\
\hline SUBJECT & 111450 & SUBJECT-MATTER & 111450 & 111450 & 0 & $0.00 \%$ \\
\hline DIRECT-HAS-MEMBER & 12113 & DIRECT-MEMBER-OF & 12113 & 12113 & 0 & $0.00 \%$ \\
\hline DIRECT-PART-OF & 8638 & DIRECT-HAS-PART & 8611 & 8624 & 27 & $0.31 \%$ \\
\hline ANTONYM & 7605 & & & 7605 & 0 & $0.00 \%$ \\
\hline IS-PERTAINED-TO-BY & 3497 & PERTAINS-TO & 3497 & 3497 & 0 & $0.00 \%$ \\
\hline SHISHKABOB & 1896 & & & 1896 & 0 & $0.00 \%$ \\
\hline DIRECT-HAS-SUBSTANCE & 1505 & DIRECT-SUBSTANCE-OF & 1502 & 1503 & 3 & $0.20 \%$ \\
\hline INSTRUMENT-OF & 918 & INSTRUMENT & 915 & 916 & 3 & $0.33 \%$ \\
\hline HAS-SPORTS-ACTIVITY & 710 & IN-DISCIPLINE & 710 & 710 & 0 & $0.00 \%$ \\
\hline THEME-OF & 486 & THEME & 489 & 487 & 3 & $0.62 \%$ \\
\hline AGENT-OF & 474 & AGENT & 495 & 484 & 21 & $4.43 \%$ \\
\hline DOMAIN-OF & 410 & DOMAIN & 414 & 412 & 4 & $0.98 \%$ \\
\hline RANGE & 389 & & & 389 & 0 & $0.00 \%$ \\
\hline LOCATION-OF & 364 & LOCATION & 364 & 364 & 0 & $0.00 \%$ \\
\hline INVERSE & 288 & & & 288 & 0 & $0.00 \%$ \\
\hline PRODUCER-OF & 183 & PRODUCED-BY & 184 & 183 & 1 & $0.55 \%$ \\
\hline SOURCE-OF & 112 & SOURCE & 116 & 114 & 4 & $3.57 \%$ \\
\hline BENEFICIARY-OF & 73 & BENEFICIARY & 75 & 74 & 2 & $2.74 \%$ \\
\hline ROLE-FOR-AREA & 69 & AREA-OF-INTEREST & 69 & 69 & 0 & $0.00 \%$ \\
\hline EMPLOYER-OF & 63 & EMPLOYED-BY & 63 & 63 & 0 & $0.00 \%$ \\
\hline MERCHANDISE-OF & 50 & HAS-MERCHANDISE & 50 & 50 & 0 & $0.00 \%$ \\
\hline CUSTOMER-OF & 47 & HAS-CUSTOMER & 48 & 47 & 1 & $2.13 \%$ \\
\hline DESTINATION-OF & 47 & DESTINATION & 47 & 47 & 0 & $0.00 \%$ \\
\hline ACCOMPANIER-OF & 41 & & & 41 & 0 & $0.00 \%$ \\
\hline OBJECT-INVOLVED & 40 & & & 40 & 0 & $0.00 \%$ \\
\hline OWNED-BY & 36 & OWNER-OF & 36 & 36 & 0 & $0.00 \%$ \\
\hline WORK-EQUIPMENT-OF & 35 & HAS-WORK-EQUIPMENT & 35 & 35 & 0 & $0.00 \%$ \\
\hline MEASURED-BY & 35 & MEASURING-DEVICE-FOR & 35 & 35 & 0 & $0.00 \%$ \\
\hline HEADED-BY & 33 & HEAD-OF & 25 & 29 & 8 & $24.24 \%$ \\
\hline CAUSED-BY & 30 & EFFECT & 29 & 29 & 1 & $3.33 \%$ \\
\hline DIRECT-DISJOINT & 26 & & & 26 & 0 & $0.00 \%$ \\
\hline CONTAINED-IN & 26 & CONTAINS & 25 & 25 & 1 & $3.85 \%$ \\
\hline PURPOSE-OF & 26 & PURPOSE & 29 & 27 & 3 & $11.54 \%$ \\
\hline PRECONDITION-OF & 24 & PRECONDITION & 24 & 24 & 0 & $0.00 \%$ \\
\hline AREA-OF-ACTIVITY & 23 & ACTIVITY-IN-AREA & 23 & 23 & 0 & $0.00 \%$ \\
\hline BORDERS-ON & 20 & & & 20 & 0 & $0.00 \%$ \\
\hline EXPERIENCER-OF & 20 & EXPERIENCER & 20 & 20 & 0 & $0.00 \%$ \\
\hline HAS-PRODUCT-TYPE & 19 & PRODUCT-TYPE-OF & 19 & 19 & 0 & $0.00 \%$ \\
\hline REPRESENTS & 18 & REPRESENTED-BY & 18 & 18 & 0 & $0.00 \%$ \\
\hline ROLE-FOR-ACTIVITY & 17 & & & 17 & 0 & $0.00 \%$ \\
\hline SUBSTRATE-OF & 15 & SUBSTRATE & 18 & 16 & 3 & $20.00 \%$ \\
\hline HAS-STANDARD-MEASURE & 15 & STANDARD-MEASURE-FOR & 15 & 15 & 0 & $0.00 \%$ \\
\hline RELIGION-OF & 14 & HAS-RELIGION & 14 & 14 & 0 & $0.00 \%$ \\
\hline AREA-OF-BUSINESS-ACTIVITY & 14 & ORGANIZATION-IN-BUSINESS-AREA & 14 & 14 & 0 & $0.00 \%$ \\
\hline SERVICES & 14 & SERVICES-OF & 14 & 14 & 0 & $0.00 \%$ \\
\hline OPERATOR-OF & 11 & OPERATED-BY & 15 & 13 & 4 & $36.36 \%$ \\
\hline MEASURED-IN & 11 & MEASURING-UNIT-FOR & 11 & 11 & 0 & $0.00 \%$ \\
\hline CONNECTS & 9 & CONNECTED-TO & 9 & 9 & 0 & $0.00 \%$ \\
\hline CONTROLLED-BY & 7 & CONTROLS & 7 & 7 & 0 & $0.00 \%$ \\
\hline AREA-STUDIED-IN & 5 & OBJECT-STUDIED-IN-AREA & 5 & 5 & 0 & $0.00 \%$ \\
\hline UPPER-LIMIT & 4 & LOWER-LIMIT & 4 & 4 & 0 & $0.00 \%$ \\
\hline HAS-AUDIENCE & 4 & AUDIENCE-OF & 4 & 4 & 0 & $0.00 \%$ \\
\hline CO-DOMAIN & 4 & & & 4 & 0 & $0.00 \%$ \\
\hline ESTABLISHED-BY & 3 & ESTABLISHER-OF & 3 & 3 & 0 & $0.00 \%$ \\
\hline HAS-NAME & 3 & NAME-OF & 3 & 3 & 0 & $0.00 \%$ \\
\hline ORIGIN & 3 & ORIGIN-OF & 3 & 3 & 0 & $0.00 \%$ \\
\hline LANGUAGE-OF & 3 & & & 3 & 0 & $0.00 \%$ \\
\hline LOCATION-WITHIN-DOCUMENT & 2 & & & 2 & 0 & $0.00 \%$ \\
\hline AUTHOR-OF & 2 & AUTHORED-BY & 2 & 2 & 0 & $0.00 \%$ \\
\hline HAS-NATIONALITY & 2 & NATIONALITY-OF & 2 & 2 & 0 & $0.00 \%$ \\
\hline HAS-CORPORATE-DIVISION & 2 & PARENT-CORPORATION-OF & 2 & 2 & 0 & $0.00 \%$ \\
\hline ELEMENT-OF & 2 & HAS-ELEMENT & 2 & 2 & 0 & $0.00 \%$ \\
\hline LESS-THAN & 2 & GREATER-THAN & 2 & 2 & 0 & $0.00 \%$ \\
\hline TEXTUAL-RELATION & 2 & COGNITIVE-RELATION & 2 & 2 & 0 & $0.00 \%$ \\
\hline OUTSIDE-OF & 1 & & & 1 & 0 & $0.00 \%$ \\
\hline HAS-REPRESENTATIVE & 1 & REPRESENTATIVE-OF & 1 & 1 & 0 & $0.00 \%$ \\
\hline HAS-CURRENCY & 1 & CURRENCY-OF & 1 & 1 & 0 & $0.00 \%$ \\
\hline SPORTS-CLUB-OF & 1 & HAS-SPORTS-CLUB & 1 & 1 & 0 & $0.00 \%$ \\
\hline HAS-COACH & 1 & $\mathrm{COACH}-\mathrm{OF}$ & 1 & 1 & 0 & $0.00 \%$ \\
\hline INSIDE-OF & 1 & & & 1 & 0 & $0.00 \%$ \\
\hline HAS-PHONE-NUMBER & 1 & PHONE-NUMBER-OF & 1 & 1 & 0 & $0.00 \%$ \\
\hline HAS-HEADQUARTERS & 1 & HEADQUARTERS-OF & 1 & 1 & 0 & $0.00 \%$ \\
\hline HAS-LABEL & 1 & LABEL-OF & 1 & 1 & 0 & $0.00 \%$ \\
\hline LANGUAGE-REPRESENTED-IN & 1 & & & 1 & 0 & $0.00 \%$ \\
\hline PARTNER-OF & 1 & HAS-PARTNER & 1 & 1 & 0 & $0.00 \%$ \\
\hline OUTCOME & 1 & & & 1 & 0 & $0.00 \%$ \\
\hline
\end{tabular}

Table 1: Link type distribution, with inverses. 


\begin{tabular}{|c|c|c|c|}
\hline Link & Count & $\%$ & Cumulative \% \\
\hline SUBCLASSES & 125696 & $45.4 \%$ & $45.4 \%$ \\
\hline SUBJECT & 111450 & $40.3 \%$ & $85.6 \%$ \\
\hline DIRECT-HAS-MEMBER & 12119 & $4.4 \%$ & $90.0 \%$ \\
\hline DIRECT-PART-OF & 8698 & $3.1 \%$ & $93.2 \%$ \\
\hline ANTONYM & 7605 & $2.7 \%$ & $95.9 \%$ \\
\hline PERTAINS-TO & 3497 & $1.3 \%$ & $97.2 \%$ \\
\hline SHISHKABOB & 1896 & $0.7 \%$ & $97.9 \%$ \\
\hline DIRECT-SUBSTANCE-OF & 1529 & $0.6 \%$ & $98.4 \%$ \\
\hline INSTRUMENT & 936 & $0.3 \%$ & $98.7 \%$ \\
\hline IN-DISCIPLINE & 710 & $0.3 \%$ & $99.0 \%$ \\
\hline AGENT & 527 & $0.2 \%$ & $99.2 \%$ \\
\hline THEME & 509 & $0.2 \%$ & $99.4 \%$ \\
\hline LOCATION & 382 & $0.1 \%$ & $99.5 \%$ \\
\hline PRODUCED-BY & 186 & $0.1 \%$ & $99.6 \%$ \\
\hline BENEFICIARY & 77 & $0.0 \%$ & $99.6 \%$ \\
\hline AREA-OF-INTEREST & 69 & $0.0 \%$ & $99.6 \%$ \\
\hline EMPLOYER-OF & 66 & $0.0 \%$ & $99.7 \%$ \\
\hline HAS-CUSTOMER & 53 & $0.0 \%$ & $99.7 \%$ \\
\hline HAS-MERCHANDISE & 50 & $0.0 \%$ & $99.7 \%$ \\
\hline DESTINATION & 50 & $0.0 \%$ & $99.7 \%$ \\
\hline HEADED-BY & 42 & $0.0 \%$ & $99.7 \%$ \\
\hline ACCOMPANIER-OF & 41 & $0.0 \%$ & $99.7 \%$ \\
\hline OBJECT-INVOLVED & 40 & $0.0 \%$ & $99.8 \%$ \\
\hline OWNER-OF & 36 & $0.0 \%$ & $99.8 \%$ \\
\hline MEASURED-BY & 35 & $0.0 \%$ & $99.8 \%$ \\
\hline HAS-WORK-EQUIPMENT & 35 & $0.0 \%$ & $99.8 \%$ \\
\hline CAUSED-BY & 32 & $0.0 \%$ & $99.8 \%$ \\
\hline PURPOSE & 30 & $0.0 \%$ & $99.8 \%$ \\
\hline PRECONDITION & 26 & $0.0 \%$ & $99.8 \%$ \\
\hline DIRECT-DISJOINT & 26 & $0.0 \%$ & $99.8 \%$ \\
\hline HEAD-OF & 25 & $0.0 \%$ & $99.9 \%$ \\
\hline CONTAINS & 25 & $0.0 \%$ & $99.9 \%$ \\
\hline AREA-OF-ACTIVITY & 23 & $0.0 \%$ & $99.9 \%$ \\
\hline HAS-PRODUCT-TYPE & 22 & $0.0 \%$ & $99.9 \%$ \\
\hline EXPERIENCER & 21 & $0.0 \%$ & $99.9 \%$ \\
\hline BORDERS-ON & 20 & $0.0 \%$ & $99.9 \%$ \\
\hline REPRESENTS & 19 & $0.0 \%$ & $99.9 \%$ \\
\hline SUBSTRATE & 18 & $0.0 \%$ & $99.9 \%$ \\
\hline ROLE-FOR-ACTIVITY & 17 & $0.0 \%$ & $99.9 \%$ \\
\hline OPERATED-BY & 16 & $0.0 \%$ & $99.9 \%$ \\
\hline AREA-OF-BUSINESS-ACTIVITY & 16 & $0.0 \%$ & $99.9 \%$ \\
\hline STANDARD-MEASURE-FOR & 15 & $0.0 \%$ & $99.9 \%$ \\
\hline HAS-STANDARD-MEASURE & 15 & $0.0 \%$ & $99.9 \%$ \\
\hline SERVICES-OF & 14 & $0.0 \%$ & $99.9 \%$ \\
\hline SERVICES & 14 & $0.0 \%$ & $99.9 \%$ \\
\hline RELIGION-OF & 14 & $0.0 \%$ & $99.9 \%$ \\
\hline ORGANIZATION-IN-BUSINESS-AREA & 14 & $0.0 \%$ & $100.0 \%$ \\
\hline HAS-RELIGION & 14 & $0.0 \%$ & $100.0 \%$ \\
\hline MEASURING-UNIT-FOR & 11 & $0.0 \%$ & $100.0 \%$ \\
\hline MEASURED-IN & 11 & $0.0 \%$ & $100.0 \%$ \\
\hline CONNECTS & 9 & $0.0 \%$ & $100.0 \%$ \\
\hline CONNECTED-TO & 9 & $0.0 \%$ & $100.0 \%$ \\
\hline CONTROLS & 7 & $0.0 \%$ & $100.0 \%$ \\
\hline CONTROLLED-BY & 7 & $0.0 \%$ & $100.0 \%$ \\
\hline OBJECT-STUDIED-IN-AREA & 5 & $0.0 \%$ & $100.0 \%$ \\
\hline AREA-STUDIED-IN & 5 & $0.0 \%$ & $100.0 \%$ \\
\hline UPPER-LIMIT & 4 & $0.0 \%$ & $100.0 \%$ \\
\hline LOWER-LIMIT & 4 & $0.0 \%$ & $100.0 \%$ \\
\hline HAS-AUDIENCE & 4 & $0.0 \%$ & $100.0 \%$ \\
\hline CO-DOMAIN & 4 & $0.0 \%$ & $100.0 \%$ \\
\hline ORIGIN & 3 & $0.0 \%$ & $100.0 \%$ \\
\hline LANGUAGE-OF & 3 & $0.0 \%$ & $100.0 \%$ \\
\hline HAS-NAME & 3 & $0.0 \%$ & $100.0 \%$ \\
\hline ESTABLISHED-BY & 3 & $0.0 \%$ & $100.0 \%$ \\
\hline TEXTUAL-RELATION & 2 & $0.0 \%$ & $100.0 \%$ \\
\hline PARENT-CORPORATION-OF & 2 & $0.0 \%$ & $100.0 \%$ \\
\hline NATIONALITY-OF & 2 & $0.0 \%$ & $100.0 \%$ \\
\hline LOCATION-WITHIN-DOCUMENT & 2 & $0.0 \%$ & $100.0 \%$ \\
\hline LESS-THAN & 2 & $0.0 \%$ & $100.0 \%$ \\
\hline HAS-ELEMENT & 2 & $0.0 \%$ & $100.0 \%$ \\
\hline AUTHORED-BY & 2 & $0.0 \%$ & $100.0 \%$ \\
\hline SPORTS-CLUB-OF & 1 & $0.0 \%$ & $100.0 \%$ \\
\hline REPRESENTATIVE-OF & 1 & $0.0 \%$ & $100.0 \%$ \\
\hline PHONE-NUMBER-OF & 1 & $0.0 \%$ & $100.0 \%$ \\
\hline PARTNER-OF & 1 & $0.0 \%$ & $100.0 \%$ \\
\hline OUTSIDE-OF & 1 & $0.0 \%$ & $100.0 \%$ \\
\hline OUTCOME & 1 & $0.0 \%$ & $100.0 \%$ \\
\hline LANGUAGE-REPRESENTED-IN & 1 & $0.0 \%$ & $100.0 \%$ \\
\hline LABEL-OF & 1 & $0.0 \%$ & $100.0 \%$ \\
\hline INSIDE-OF & 1 & $0.0 \%$ & $100.0 \%$ \\
\hline HEADQUARTERS-OF & 1 & $0.0 \%$ & $100.0 \%$ \\
\hline HAS-CURRENCY & 1 & $0.0 \%$ & $100.0 \%$ \\
\hline $\mathrm{HAS}-\mathrm{COACH}$ & 1 & $0.0 \%$ & $100.0 \%$ \\
\hline
\end{tabular}

Table 2: Combined link type distribution, classes and properties only. 


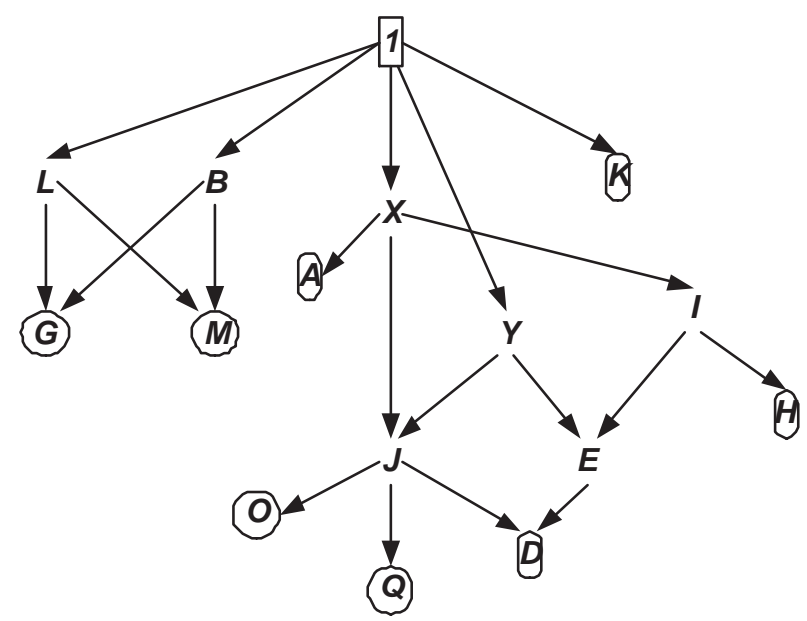

Figure 1: An example ordered set.

Thus we need to consider vertical position dually from the top and bottom. We do this by first providing a global bottom node 0 below all of the leaves $(G, M, O, Q, D, H, K)$. Then for two nodes $a, b \in P$, we let $h^{*}(a, b)$ be the maximum path length between them, and the height to be the ax chain length from the top to the bottom: $\mathcal{H}:=h^{*}(0,1)$. We than have the following quantities:

Top Rank: Max chain length $a$ to top: $r^{t}(a):=h^{*}(a, 1)$

Bottom Rank: Height minus max chain length from the bottom to $a: r^{b}(a):=\mathcal{H}-h^{*}(0, b)$

Interval Rank: $R(a):=\left[r^{t}(a), r^{b}(a)\right]$

Rank Width: $W(a):=\|R(a)\|=r^{b}(a)-r^{t}(a)$

Fig. 2 shows the resulting structure (also showing some additional features [3]). For example, we have $\mathcal{H}=5$, and $R(K)=[1,4]$, so that $K$ has a top rank of 1 , a bottom rank of 4 , and a rank width of 3 . This is maximal, because $K$ is both "one down from the top" and also "one up from the bottom". This is contrasted with $R(I)=[2,2]$, so that it is unequivocally at rank 2 , being 2 down from the top and 3 up from the bottom.

\section{Subclass}

We next consider a hierarchical analysis specifically of the SUBCLASS hierarchy.

A connection analysis reveals that Omega is essentially "is-a complete": there is one giant component of 121,655 nodes, and eight components of size one due to erroneous roots (see below).

Table 3 shows a portion of the distribution of the number of parents and children. This shows a largely, but not completely, tree-like structure, with $3.0 \%$ of the nodes having more than one parent, and seven nodes having six.

Table 4 and Fig. 3 show the rank distribution.

We note a few things. 


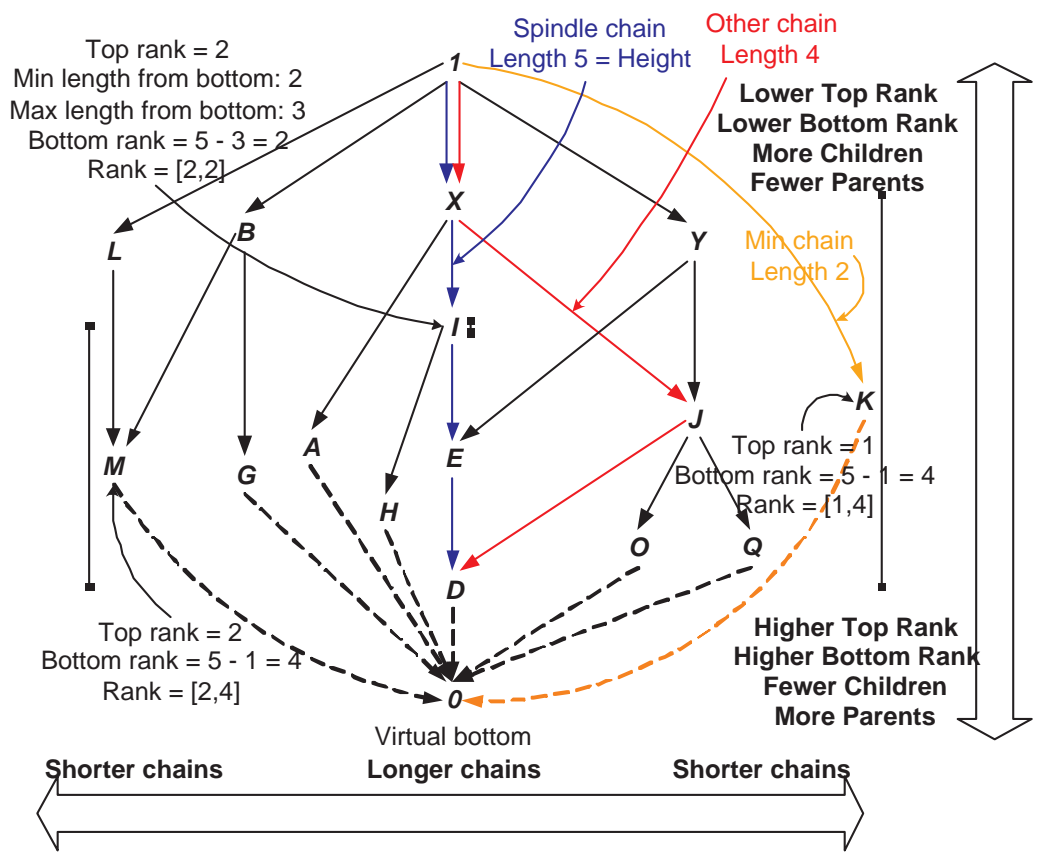

Figure 2: Rank layout.

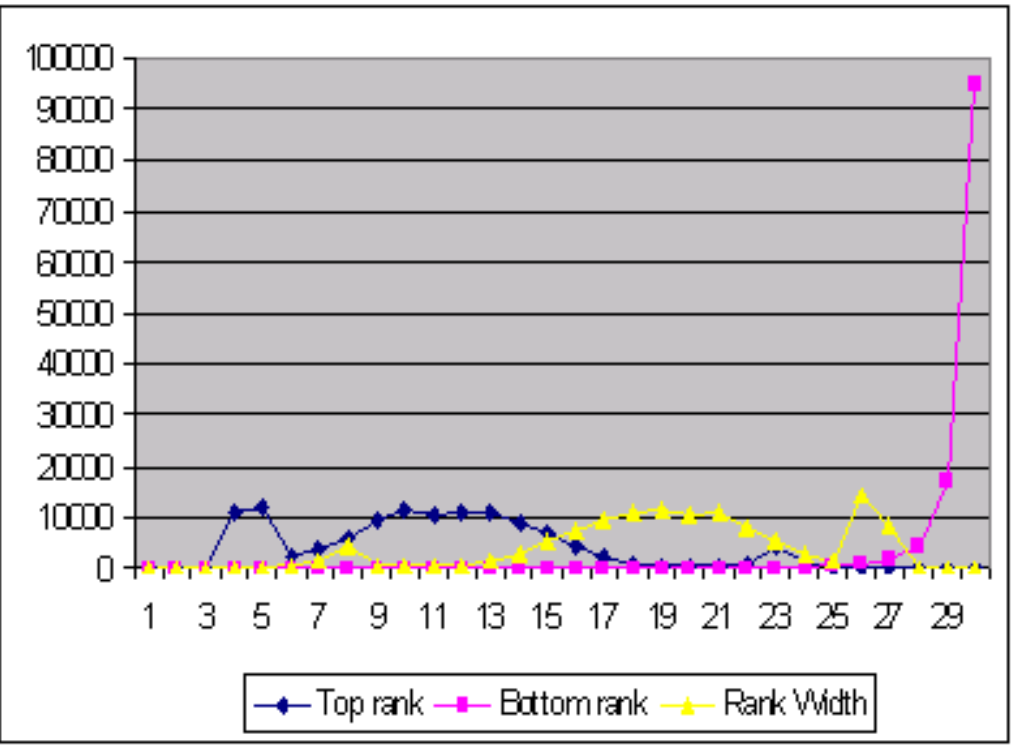

Figure 3: Subclass rank distribution. 


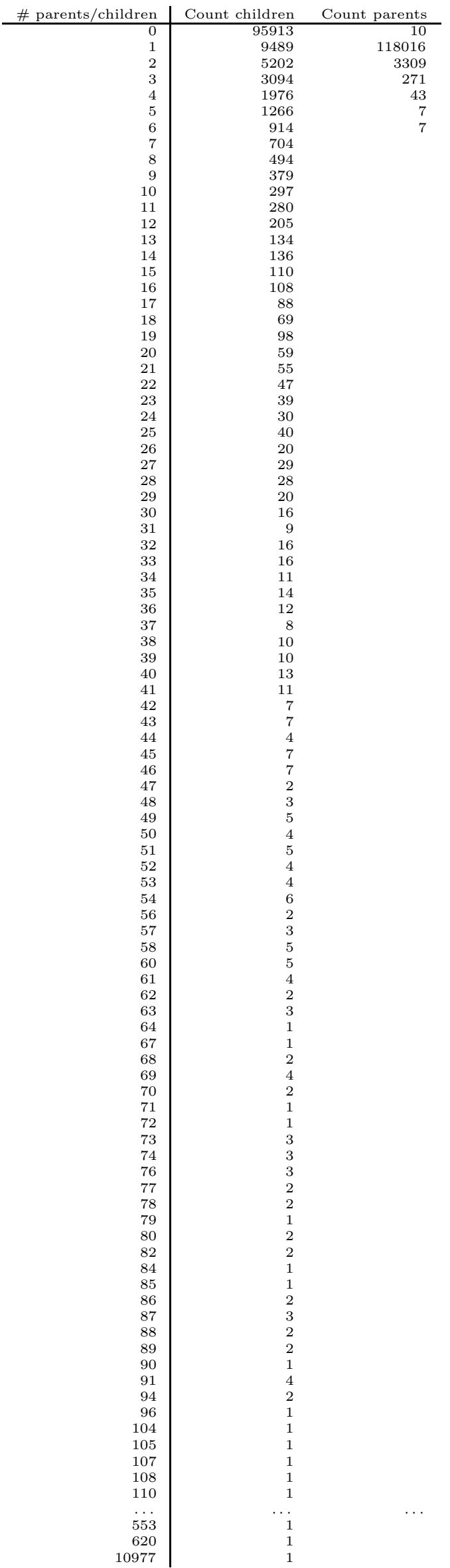

Table 3: Subclass parent/children node distribution. 


\begin{tabular}{r|rrr} 
& Top Rank & Bottom Rank & Width \\
\hline 0 & 10 & 1 & 74 \\
1 & 9 & 1 & 111 \\
2 & 39 & 2 & 124 \\
3 & 11124 & 3 & 100 \\
4 & 12176 & 4 & 144 \\
5 & 2272 & 2 & 324 \\
6 & 4172 & 3 & 1636 \\
7 & 6167 & 2 & 4387 \\
8 & 9475 & 3 & 734 \\
9 & 11384 & 3 & 355 \\
10 & 10675 & 2 & 315 \\
11 & 10851 & 2 & 686 \\
12 & 10790 & 3 & 1675 \\
13 & 8788 & 5 & 3227 \\
14 & 6759 & 6 & 5570 \\
15 & 4689 & 8 & 7671 \\
16 & 2505 & 7 & 9453 \\
17 & 1192 & 16 & 11108 \\
18 & 465 & 22 & 11311 \\
19 & 308 & 24 & 10473 \\
20 & 373 & 48 & 11107 \\
21 & 834 & 66 & 8156 \\
22 & 4362 & 123 & 5398 \\
23 & 1580 & 236 & 3218 \\
24 & 219 & 433 & 1451 \\
25 & 121 & 881 & 14483 \\
26 & 105 & 1882 & 8338 \\
27 & 126 & 4617 & 25 \\
28 & 78 & 17345 & \\
29 & 15 & 95913 & 8 \\
& & &
\end{tabular}

Table 4: Subclass rank distributions.

- The height $\mathcal{H}=29$.

- There are actually 10 roots (top rank $=0$ ). These are undoubdtedly errors, and are shown in Table 5. We have developed the following opinions:

AdministrativeDivision: might be mistyped factbook: AdministrativeDivision, which occurs in tree

Building: Might be referring to BUILDING?

COMPUTER_MEDIATED_COMMUNICATION_APPLICATION-SUBJECT: Misspelling of COMPUTER_MEDIATED_COMMUNICATION_APPLICATIONS-SUBJECT (note extra 'S')

fiber-optics: Misspelling of fiber-optic

owl:Thing: In the Omega ontology, unclear why its not under Summum Genus

JointVentureEvent, CellularPhone, TELLECOMMUNICATION-SUBJECT, TELECOMMUNICATIONS: All are instances of SUBJECT, but some SUBJECTS are also treated as classes.

- There are 95,913 leaves (bottom rank $=29$ ), or $78.8 \%$ of the structure.

- The behvaior of the top and bottom ranks are generally as expected. There's a broad fan-out down the structure, tapering towards the bottom, indicated by the generally unimodal top rank distribution and the increasing bottom rank distribution. The trailing spike in bottom rank is the appearance of the leaves.

- Some distinct discrepancies are apparent:

- An initial spike in top rank at 3 and 4 indicates a distinct collection of nodes at that level. 
fiber-optics

JointVentureEvent

TELECOMMUNICATION-SUBJECT

Summum_Genus

Building

NOTHING*

TELECOMMUNICATIONS

TELECOMMUNICATIONS

AdministrativeDivision

CellularPhone

PHYSICAL-OBJECT

owl:Thing

Table 5: Root nodes in SUBCLASSES.

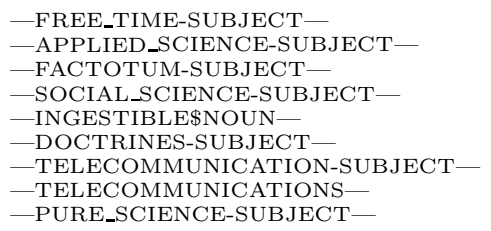

Table 6: Roots of the large SUBJECT component.

- A corresponding spike in rank width at 25 and 26 indicates that the bulk of those nodes are, in fact, leaves.

- Another bump in rank width at 6 and 7 correlates to a spike in top rank around 22 and 23. This needs more explanation.

\section{$5 \quad$ Subject}

An analysis of SUBJECT reveals the following:

- A single, large component of 100,313 nodes with the nine roots shown in Table 6 .

- A component of size four with two roots: -ARTISTIC-ACTIVITY - and -POLL—, and two children, - EVENT — and — OBJECT—, which both mutually multiply inherit.

- A component of size two with the single root

-COMPUTER_MEDIATED_COMMUNICATION_APPLICATION-SUBJECT — and child "bbs".

- 21,344 lone nodes, comprising $17.5 \%$ of the structure.

The parents/children distribution for the large component is shown in Table 7 . We see a shallow hierarchy (height $\mathcal{H}=5$ ) with vast fanout, many many nodes having large numbers of children. The 25 nodes with more than 1000 children is shown in Table 8. Note that one, -FACTOTUMSUBJECT - is also a root. But, the amount of multiple inheritance is also moderately high at $9.7 \%$ of the structure. There is thus a complex structure here, which will require substantially more analysis to fully understand.

Table 9 shows the rank distribution for the large component, while Fig. 4 shows this graphically. There are the nine roots we saw before, and then a very shallow structure, with the vast bulk of 


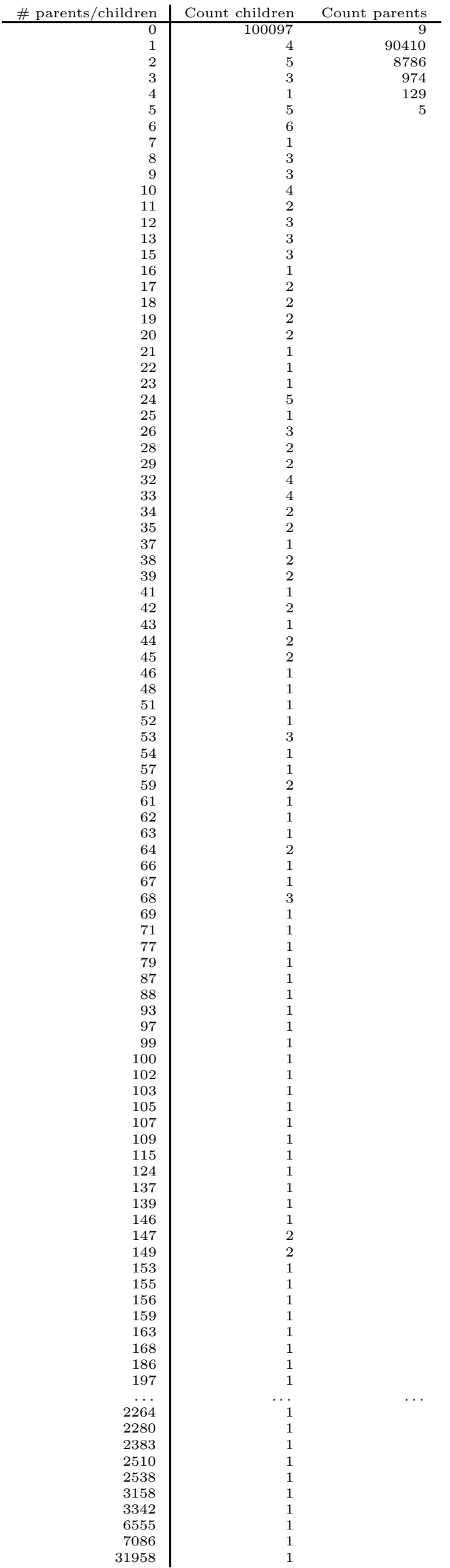

Table 7: Subject parent/children node distribution. 


\begin{tabular}{|c|c|c|}
\hline Node & \# Parents & \# Children \\
\hline -FACTOTUM-SUBJECT & 0 & 31958 \\
\hline —ZOOLOGY-SUBJECT— & 1 & 7086 \\
\hline —BOTANY-SUBJECT— & 1 & 6555 \\
\hline —BIOLOGY-SUBJECT—- & 1 & 3342 \\
\hline —GEOGRAPHY-SUBJECT- & 1 & 3158 \\
\hline —GASTRONOMY-SUBJECT- & 1 & 2538 \\
\hline -MEDICINE-SUBJECT- & 1 & 2510 \\
\hline —CHEMISTRY-SUBJECT- & 1 & 2383 \\
\hline —QUALITY-SUBJECT— & 1 & 2280 \\
\hline - ANATOMY-SUBJECT- & 1 & 2264 \\
\hline —ADMINISTRATION-SUBJECT- & 1 & 2232 \\
\hline —PERSON-SUBJECT- & 1 & 1985 \\
\hline -BUILDING_INDUSTRY-SUBJECT- & 1 & 1715 \\
\hline 一RELIGION-SUBJECT- & 1 & 1601 \\
\hline —MILITARY-SUBJECT- & 1 & 1517 \\
\hline —LINGUISTICS-SUBJECT- & 1 & 1486 \\
\hline —LAW-SUBJECT— & 1 & 1436 \\
\hline —PSYCHOLOGY-SUBJECT- & 1 & 1366 \\
\hline —METROLOGY-SUBJECT- & 1 & 1350 \\
\hline —ECONOMY-SUBJECT— & 1 & 1276 \\
\hline —TRANSPORT-SUBJECT_- & 1 & 1143 \\
\hline —PHYSICS-SUBJECT- & 1 & 1068 \\
\hline —POLITICS-SUBJECT- & 1 & 1013 \\
\hline —INDUSTRY-SUBJECT- & 1 & 1009 \\
\hline —MUSIC-SUBJECT- & 1 & 1005 \\
\hline
\end{tabular}

Table 8: Subject nodes with $>1000$ children.

\begin{tabular}{r|rrr} 
& Top Rank & Bottom Rank & Width \\
\hline 0 & 9 & 1 & 11 \\
1 & 32213 & 4 & 1947 \\
2 & 32297 & 7 & 33990 \\
3 & 33898 & 40 & 32199 \\
4 & 1890 & 164 & 32166 \\
5 & 6 & 100097 &
\end{tabular}

Table 9: Rank distributions for Subject large component.

the nodes living between top ranks 1 and 3, tracking the large number of single-node components. There are far more leaves here, $90.1 \%$ of the structure.

\section{Member}

An analysis of DIRECT-HAS-MEMBER reveals the distribution of component sizes shown in Table 10. We note:

- There are 109,059 lone nodes comprising $89.6 \%$ of the structure; or, in other words, only $10.4 \%$ of the structure is actually included within the MEMBER hierarchy.

- The one largest component with 5,291 members has $4.4 \%$ of the structure.

- The second largest component with 4,688 members as $3.9 \%$ of the structure.

The number of roots and leaves of the components with five or more elements is shown in Table 11, with the roots shown for any with one or two roots.

We can observe the following about the two largest components:

ID 241: 5291 nodes, height $\mathcal{H}=11$. Its 13 roots are show in Table 12, its parents/children distribution in Table 13, and its rank distribution in Table 14. There is very little multiple inheritance, with only $0.4 \%$ of the structure having more than one parent. $53.7 \%$ are leaves. 


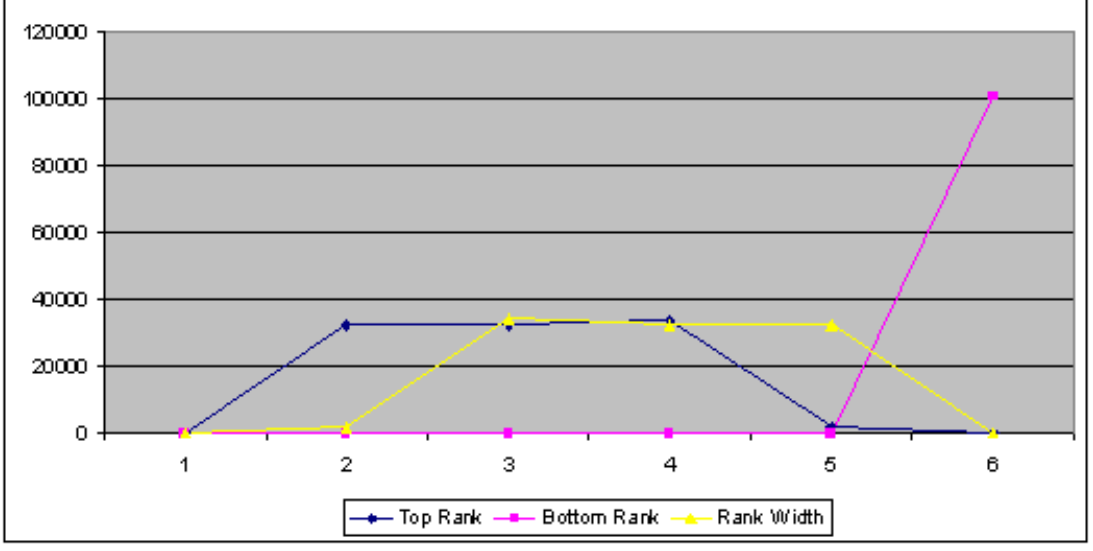

Figure 4: Rank distribution of Subject large component.

\begin{tabular}{r|r} 
Size & \# Components \\
\hline 5291 & 1 \\
4688 & 1 \\
515 & 1 \\
177 & 1 \\
150 & 1 \\
124 & 1 \\
66 & 1 \\
26 & 1 \\
25 & 1 \\
21 & 1 \\
20 & 1 \\
17 & 3 \\
15 & 1 \\
14 & 2 \\
13 & 2 \\
12 & 1 \\
11 & 2 \\
10 & 5 \\
9 & 2 \\
8 & 3 \\
7 & 6 \\
6 & 2 \\
5 & 19 \\
4 & 25 \\
3 & 72 \\
2 & 395 \\
1 & 109059
\end{tabular}

Table 10: Component distribution for DIRECT-HAS-MEMBER. 


\begin{tabular}{|c|c|c|c|c|c|}
\hline Compid & Size & Height & \# Roots & \# Leaves & $\operatorname{Root}(\mathrm{s})$ \\
\hline 241 & 5291 & 11 & 13 & 2843 & \\
\hline 252 & 4688 & 9 & 1 & 2779 & -Plantae- \\
\hline 2902 & 515 & 8 & 1 & 305 & -Fungi- \\
\hline 2738 & 177 & 7 & 1 & 87 & -Protoctista- \\
\hline 231 & 150 & 2 & 8 & 80 & \\
\hline 3227 & 124 & 6 & 1 & 59 & -Monera- \\
\hline 8529 & 66 & 3 & 1 & 40 & —Ericaceae- \\
\hline 7592 & 26 & 1 & 1 & 25 & -Roman_alphabet_- \\
\hline 8474 & 25 & 1 & 1 & 24 & -Greek_alphabet- \\
\hline 4558 & 21 & 1 & 5 & 16 & \\
\hline 7636 & 20 & 5 & 1 & 11 & -Phaeophyta- \\
\hline 7568 & 17 & 1 & 1 & 16 & -Hebrew_alphabet_- \\
\hline 633 & 17 & 2 & 1 & 12 & -CIS- \\
\hline 18645 & 17 & 3 & 1 & 12 & _football_league- \\
\hline 17187 & 15 & 1 & 1 & 14 & -US_Cabinet- \\
\hline 4545 & 14 & 2 & 4 & 9 & \\
\hline 1627 & 14 & 7 & 1 & 7 & —-kingdom $¿$ Fungi- \\
\hline 575 & 13 & 1 & 2 & 11 & —Dixie-, -Deep_South— \\
\hline 12365 & 13 & 1 & 1 & 12 & —solar_system- \\
\hline 875 & 12 & 2 & 4 & 7 & \\
\hline 26389 & 11 & 1 & 1 & 10 & —fishing_gear- \\
\hline 46588 & 11 & 2 & 1 & 6 & -Scorpaenidae- \\
\hline 14095 & 10 & 5 & 2 & 2 & —army-,-regiment- \\
\hline 16358 & 10 & 1 & 1 & 9 & _baseball_team- \\
\hline 22704 & 10 & 1 & 1 & 9 & _Hanseatic_League- \\
\hline 5272 & 10 & 3 & 1 & 5 & -U.S. - - - \\
\hline 28295 & 10 & 2 & 1 & 5 & -Hinduism $\_$Brahminism- \\
\hline 6102 & 9 & 1 & 1 & 8 & $-\mathrm{UN}-$ \\
\hline 29338 & 9 & 1 & 1 & 8 & -British_Cabinet- \\
\hline 17039 & 8 & 1 & 1 & 7 & —wedding- \\
\hline 27490 & 8 & 1 & 1 & 7 & -Soviet_Russia_- \\
\hline 3221 & 8 & 1 & 1 & 7 & —amphibole_group_- \\
\hline 5815 & 7 & 1 & 3 & 4 & \\
\hline 2154 & 7 & 1 & 3 & 4 & \\
\hline 58812 & 7 & 1 & 2 & 5 & -Windsor-,-Saxe-Coburg-Gotha- \\
\hline 58805 & 7 & 1 & 1 & 6 & -Hohenzollern- \\
\hline 14574 & 7 & 1 & 1 & 6 & -Bloomsbury_Group- \\
\hline 6645 & 7 & 1 & 1 & 6 & —royalty\&lt;house-- \\
\hline 38627 & 6 & 1 & 1 & 5 & - Cyperus- \\
\hline 6894 & 6 & 3 & 1 & 3 & —military- \\
\hline 13497 & 5 & 1 & 3 & 2 & \\
\hline 907 & 5 & 1 & 2 & 3 & —nurse-patient_relation-, - doctor-patient_relation- \\
\hline 8497 & 5 & 2 & 2 & 2 & $-\operatorname{cosmos}-,-$ constellation $¿$ Ara- \\
\hline 58817 & 5 & 1 & 1 & 4 & —Tudor\&lt;dynasty_- \\
\hline 48335 & 5 & 1 & 1 & 4 & - tea_set- \\
\hline 21872 & 5 & 1 & 1 & 4 & -Beatles- \\
\hline 32704 & 5 & 1 & 1 & 4 & -Home_Counties- \\
\hline 23465 & 5 & 1 & 1 & 4 & - Centaurus- \\
\hline 37782 & 5 & 1 & 1 & 4 & —Marx_Brothers- \\
\hline 70551 & 5 & 1 & 1 & 4 & -Siberia- \\
\hline 6808 & 5 & 2 & 1 & 3 & -navy- \\
\hline 6839 & 5 & 2 & 1 & 3 & —ship's_company_- \\
\hline 44823 & 5 & 2 & 1 & 3 & - congeries - \\
\hline 26639 & 5 & 2 & 1 & 3 & —electorate- \\
\hline 7522 & 5 & 2 & 1 & 3 & —Taurus\&lt;constellation- \\
\hline 21011 & 5 & 2 & 1 & 3 & _basketball_league- \\
\hline 12147 & 5 & 3 & 1 & 2 & —underworld\&lt;class- \\
\hline 70957 & 5 & 2 & 1 & 2 & -Giraffidae- \\
\hline 76288 & 5 & 2 & 1 & 2 & —parliament- \\
\hline
\end{tabular}

Table 11: Component details for MEMBER components with more five or more elements; roots shown for those with one or two roots. 


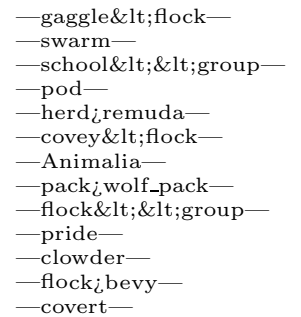

Table 12: Roots for the MEMBER largest component.

\begin{tabular}{|c|c|c|}
\hline \# parents/children & Count children & Count parents \\
\hline 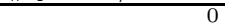 & 2843 & 13 \\
\hline 1 & 1561 & 5255 \\
\hline 2 & 360 & 21 \\
\hline 3 & 199 & 2 \\
\hline 4 & 100 & \\
\hline 5 & 63 & \\
\hline 6 & 43 & \\
\hline 7 & 21 & \\
\hline 8 & 24 & \\
\hline 9 & 25 & \\
\hline 10 & 13 & \\
\hline 11 & 7 & \\
\hline 12 & 3 & \\
\hline 13 & 3 & \\
\hline 14 & 1 & \\
\hline 15 & 2 & \\
\hline 16 & 3 & \\
\hline 18 & 5 & \\
\hline 19 & 1 & \\
\hline 20 & 3 & \\
\hline 22 & 2 & \\
\hline 23 & 1 & \\
\hline 25 & 1 & \\
\hline 26 & 1 & \\
\hline 28 & 1 & \\
\hline 33 & 1 & \\
\hline 35 & 2 & \\
\hline 40 & 1 & \\
\hline 56 & 1 & \\
\hline
\end{tabular}

Table 13: Parent/children node distribution for member component \# 241.

ID 252, Plantae: 4688 nodes, height $\mathcal{H}=9$. Its parent/child and rank distributions are shown in Tables 15 and 16. This is a pure tree (no multiple inheritance), with $52.5 \%$ of the nodes being leaves.

\section{$7 \quad$ Part Of}

An analysis of DIRECT-HAS-PART reveals the distribution of component sizes shown in Table 17. This is even less connected, with 111,968 lone nodes, and one largest component with only 5,915 members, or $4.5 \%$ of the structure. We note:

- The bulk of the ontology is not included in PART-OF, with 111,960 lone nodes comprising $92.0 \%$ of the structure; or, in other words, only $8.0 \%$ of the structure is actually included within the PART-OF hierarchy.

- In general the distribution is much flatter than MEMBER, with far more smaller components.

- The one largest component with 2,564 members has $2.1 \%$ of the structure. 


\begin{tabular}{r|rrr} 
& Top Rank & Bottom Rank & Width \\
\hline 0 & 13 & 1 & 28 \\
1 & 34 & 1 & 176 \\
2 & 73 & 1 & 1341 \\
3 & 168 & 3 & 1256 \\
4 & 338 & 4 & 1145 \\
5 & 624 & 9 & 680 \\
6 & 906 & 18 & 386 \\
7 & 1140 & 50 & 145 \\
8 & 1192 & 154 & 71 \\
9 & 719 & 586 & 38 \\
10 & 80 & 1621 & 25 \\
11 & 4 & 2843 &
\end{tabular}

Table 14: Rank distributions for member component \# 241.

\begin{tabular}{|c|c|c|}
\hline \# parents/children & Count children & Count parents \\
\hline 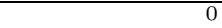 & 2779 & 1 \\
\hline 1 & 1278 & 4687 \\
\hline 2 & 269 & \\
\hline 3 & 126 & \\
\hline 4 & 52 & \\
\hline 5 & 51 & \\
\hline 6 & 23 & \\
\hline 7 & 18 & \\
\hline 8 & 15 & \\
\hline 9 & 8 & \\
\hline 10 & 10 & \\
\hline 11 & 5 & \\
\hline 12 & 5 & \\
\hline 13 & 6 & \\
\hline 14 & 3 & \\
\hline 15 & 7 & \\
\hline 16 & 5 & \\
\hline 17 & 4 & \\
\hline 18 & 1 & \\
\hline 19 & 3 & \\
\hline 20 & 2 & \\
\hline 22 & 1 & \\
\hline 24 & 1 & \\
\hline 25 & 4 & \\
\hline 28 & 2 & \\
\hline 29 & 1 & \\
\hline 30 & 1 & \\
\hline 31 & 1 & \\
\hline 50 & 1 & \\
\hline 51 & 1 & \\
\hline 54 & 1 & \\
\hline 68 & 1 & \\
\hline 77 & 1 & \\
\hline 103 & 1 & \\
\hline 176 & 1 & \\
\hline
\end{tabular}

Table 15: Parent/children node distribution for member component \# 252.

\begin{tabular}{r|rrr} 
& Top Rank & Bottom Rank & Width \\
\hline 0 & 1 & 1 & 388 \\
1 & 12 & 1 & 2954 \\
2 & 18 & 1 & 923 \\
3 & 54 & 2 & 199 \\
4 & 123 & 7 & 145 \\
5 & 234 & 18 & 46 \\
6 & 501 & 55 & 17 \\
7 & 1688 & 250 & 8 \\
8 & 1826 & 1574 & 8 \\
9 & 231 & 2779 &
\end{tabular}

Table 16: Rank distributions for member component \# 252. 


\begin{tabular}{r|r} 
Size & \# Components \\
\hline 2564 & 1 \\
967 & 1 \\
786 & 1 \\
96 & 1 \\
89 & 1 \\
88 & 1 \\
36 & 1 \\
31 & 1 \\
28 & 1 \\
27 & 1 \\
25 & 1 \\
24 & 1 \\
23 & 2 \\
20 & 3 \\
19 & 2 \\
18 & 1 \\
17 & 1 \\
16 & 2 \\
15 & 2 \\
14 & 1 \\
13 & 7 \\
12 & 4 \\
11 & 8 \\
10 & 9 \\
9 & 11 \\
8 & 13 \\
7 & 11 \\
6 & 33 \\
5 & 54 \\
4 & 74 \\
3 & 308 \\
2 & 1201 \\
1 & 111960 \\
&
\end{tabular}

Table 17: Component distribution for DIRECT-HAS-PART.

- The second largest component with 967 members as $0.8 \%$ of the structure.

The number of roots and leaves of the components with nine or more elements is shown in Table 18 , with the roots shown for any with one or two roots. This list requires more analysis, as in many cases the height and the number of roots and leaves is not as was to have ben expected.

Because of the complex component structure, the rank structure is not very meaningful, and we show the parents/children distribution in Table 19 unioned over all components. We see a moderate amount of multiple inheritance, comprising $6.0 \%$ of the structure, and including some nodes with up to 19 parents.

\section{Conclusions and Next Steps}

The purpose of this initial work was to understand the nature of the Omega ontology, and to verify its appropriateness for subsequent development of dispersion measures of query results.

We have verified that Omega is broadly hierarchical, with $93.2 \%$ of link instances participating in hierarhical link types. Additionally, Omega is is-a complete, dominated by a single class hierarchy with multiple inheritance.

Next steps in our work include:

New Version of Omega: A new version of Omega is due to be released in January, 2010. We look forward to repeating this analysis on that version.

Inherit Relations: In Omega properties are inherited down the subclass hierarchy. We can calculate the link distributional statistics modified by such inheritance. 


\begin{tabular}{|c|c|c|c|c|c|}
\hline Compid & Size & Height & \# Roots & \# Leaves & Root(s) \\
\hline 228 & 2564 & 7 & 38 & 1980 & \\
\hline 131 & 967 & 9 & 250 & 530 & \\
\hline 417 & 786 & 9 & 57 & 523 & \\
\hline 440 & 96 & 7 & 6 & 63 & \\
\hline 4893 & 89 & 3 & 16 & 60 & \\
\hline 8454 & 88 & 3 & 5 & 70 & \\
\hline 5456 & 36 & 3 & 5 & 24 & \\
\hline 3819 & 31 & 3 & 1 & 27 & -Bible- \\
\hline 15374 & 28 & 2 & 1 & 25 & —body_armor- \\
\hline 10301 & 27 & 4 & 7 & 14 & \\
\hline 15084 & 25 & 2 & 22 & 2 & \\
\hline 20049 & 24 & 10 & 3 & 3 & \\
\hline 3290 & 23 & 2 & 1 & 20 & —electromagnetic_spectrum- \\
\hline 6087 & 23 & 9 & 1 & 11 & —day ¿today- \\
\hline 7817 & 20 & 2 & 1 & 18 & -welkin- \\
\hline 8028 & 20 & 1 & 18 & 2 & \\
\hline 38458 & 20 & 8 & 4 & 9 & \\
\hline 10639 & 19 & 3 & 2 & 14 & -meiosis-, - mitosis- \\
\hline 21380 & 19 & 1 & 2 & 17 & —tag\&lt;\&lt;game-,-baseball— \\
\hline 401 & 18 & 2 & 1 & 12 & -Jewish_calendar- \\
\hline 3876 & 17 & 1 & 3 & 14 & \\
\hline 6806 & 16 & 2 & 2 & 12 & —paper\&lt;press-, - mag- \\
\hline 11138 & 16 & 4 & 1 & 7 & - angiosperm- \\
\hline 18632 & 15 & 2 & 1 & 13 & _wind_scale-_ \\
\hline 35688 & 15 & 13 & 1 & 2 & $-\mathrm{t}-$ \\
\hline 384 & 14 & 2 & 1 & 12 & - church- \\
\hline 87 & 13 & 4 & 6 & 4 & \\
\hline 3820 & 13 & 2 & 1 & 11 & —publication\&lt;work- \\
\hline 5160 & 13 & 2 & 1 & 8 & -church_calendar- \\
\hline 6655 & 13 & 1 & 1 & 12 & -Hindu_calendar- \\
\hline 11364 & 13 & 12 & 1 & 1 & $-\mathrm{mym}-$ \\
\hline 32158 & 13 & 1 & 1 & 12 & -Revolutionary_calendar- \\
\hline 56711 & 13 & 1 & 1 & 12 & -Muhammadan_calendar- \\
\hline 1441 & 12 & 2 & 3 & 7 & \\
\hline 2846 & 12 & 2 & 3 & 7 & \\
\hline 3163 & 12 & 2 & 3 & 8 & \\
\hline 5037 & 12 & 2 & 1 & 10 & —adulthood- \\
\hline 1269 & 11 & 2 & 3 & 7 & \\
\hline 2063 & 11 & 3 & 3 & 5 & \\
\hline 4784 & 11 & 2 & 1 & 7 & -meal_- \\
\hline 5934 & 11 & 4 & 1 & 7 & - cows- \\
\hline 14205 & 11 & 3 & 3 & 4 & \\
\hline 14799 & 11 & 3 & 1 & 7 & —temple\&lt;building- \\
\hline 18442 & 11 & 1 & 1 & 10 & -ATHLETICS-DECATHLON- \\
\hline 21786 & 11 & 2 & 1 & 9 & —harness\&lt;tack- \\
\hline 1484 & 10 & 2 & 4 & 5 & \\
\hline 1911 & 10 & 2 & 2 & 7 & $-\operatorname{road}_{i \text { line }-,- \text { driveway }-}$ \\
\hline 2188 & 10 & 2 & 7 & 2 & \\
\hline 5148 & 10 & 1 & 4 & 6 & \\
\hline 10138 & 10 & 2 & 2 & 7 & —amphibian ¿toad-,- - fish ¿spawner- \\
\hline 19468 & 10 & 1 & 9 & 1 & \\
\hline 20048 & 10 & 9 & 1 & 1 & -megaton- \\
\hline 37889 & 10 & 2 & 1 & 7 & -Cenozoic- \\
\hline 40632 & 10 & 2 & 2 & 7 & —chimney-, - cookstove- \\
\hline 307 & 9 & 1 & 1 & 8 & - cards- \\
\hline 1118 & 9 & 4 & 1 & 5 & - space- \\
\hline 2311 & 9 & 1 & 3 & 6 & \\
\hline 9206 & 9 & 2 & 1 & 7 & _lower_respiratory_tract_- \\
\hline 11425 & 9 & 6 & 1 & 2 & —circumference\&lt;length- \\
\hline 14212 & 9 & 2 & 1 & 7 & - links- \\
\hline 18615 & 9 & 3 & 1 & 5 & - atmosphere\&lt;gas- \\
\hline 20351 & 9 & 1 & 6 & 3 & \\
\hline 31949 & 9 & 2 & 1 & 7 & —prehistory- \\
\hline 34651 & 9 & 2 & 1 & 7 & -Paleozoic- \\
\hline 37987 & 9 & 8 & 1 & 1 & _cubic_kilometer- \\
\hline
\end{tabular}

Table 18: Component details for PART-OF components with nine or more elements; roots shown for those with one or two roots. 


\begin{tabular}{|c|c|c|}
\hline \# parents/children & Count children & Count parents \\
\hline 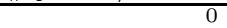 & 117950 & 114358 \\
\hline 1 & 2409 & 6467 \\
\hline 2 & 591 & 639 \\
\hline 3 & 226 & 119 \\
\hline 4 & 132 & 40 \\
\hline 5 & 69 & 8 \\
\hline 6 & 58 & 10 \\
\hline 7 & 41 & 3 \\
\hline 8 & 40 & 3 \\
\hline 9 & 26 & 1 \\
\hline 10 & 16 & 4 \\
\hline 11 & 13 & 1 \\
\hline 12 & 20 & 2 \\
\hline 13 & 8 & 2 \\
\hline 14 & 8 & 1 \\
\hline 15 & 6 & 2 \\
\hline 16 & 7 & 0 \\
\hline 17 & 4 & 0 \\
\hline 18 & 3 & 1 \\
\hline 19 & 3 & 1 \\
\hline 20 & 2 & 0 \\
\hline 21 & 3 & 0 \\
\hline 22 & 1 & 0 \\
\hline 23 & 2 & 0 \\
\hline 25 & 3 & 0 \\
\hline 29 & 4 & 0 \\
\hline 31 & 3 & 0 \\
\hline 33 & 1 & 0 \\
\hline 36 & 2 & 0 \\
\hline 37 & 2 & 0 \\
\hline 41 & 1 & 0 \\
\hline 42 & 1 & 0 \\
\hline 44 & 2 & 0 \\
\hline 49 & 1 & 0 \\
\hline 50 & 1 & 0 \\
\hline 61 & 1 & 0 \\
\hline 62 & 1 & 0 \\
\hline 64 & 1 & 0 \\
\hline 76 & 1 & 0 \\
\hline
\end{tabular}

Table 19: Part-Of parent/children node distribution unioned across all components.

Long HAS-PART Components: Some components of the HAS-PART link type are very odd. For example, component ID 11364, headed by the single root mym, has size 13 and height 12 . Essentially, it is a single chain. Other components are anomolously high. This needs to be examined.

Combine Link Types: While each of the three hierarchical link types SUBCLASSES, DIRECT-HAS-MEMBER and DIRECT-PART-OF is individually hierarchical, together they may or may not be. We will examine each of the four unions available (the three pairs and the single three-way union) to understand if they introduce any cycles. If not, it will enrich the amount of multiple inheritance in the class hierarchy.

Examine Queries: We will work with the sponsor to receive and understand appropriate test queries and/or result sets.

Centroid and Dispersion Measures: Finally we will proceed on our central task, to develop measures of centroid and dispersion appropriate for hierarchically-structured ontologies.

\section{References}

[1] Davey, BA and Priestly, HA: (1990) Introduction to Lattices and Order, Cambridge UP, Cambridge UK, 2nd Edition

[2] Joslyn, Cliff: (2004) "Poset Ontologies and Concept Lattices as Semantic Hierarchies", in: Conceptual 
Structures at Work, Lecture Notes in Artificial Intelligence, v. 3127, ed. Wolff, Pfeiffer and Delugach, pp. 287-302, Springer-Verlag, Berlin

[3] Joslyn, Cliff; Mniszewski, SM; Smith, SA; and Weber, PM: (2006) "SpindleViz: A Three Dimensional, Order Theoretical Visualization Environment for the Gene Ontology", in: Joint BioLINK and 9th Bio-Ontologies Meeting (JBB 06), http://www.bio-ontologies .org. uk/2006/download/Joslyn2EtAlSpindleviz.pdf

[4] Philpot, Andrew; Hovy, Eduard; and Pantel, Patrick: (2005) "The Omega Ontology", Proc. OntoLex 2005 - Ontologies and Lexical Resources 